\title{
Social Marketing for Restraining the Violence of the Supporters by Behaviour Change
}

\author{
Edson Coutinho da Silva ${ }^{1} \&$ Alexandre Luzzi Las Casas ${ }^{2}$ \\ ${ }^{1}$ University Center FEI, São Bernardo do Campo, Brazil \\ ${ }^{2}$ Pontifical Catholic University of São Paulo, São Paulo, Brazil \\ Correspondence: Edson Coutinho da Silva, University Center FEI, São Bernardo do Campo, Brazil.
}

Received: May 29, 2019

doi:10.5430/ijba.v10n4p64
Accepted: June 18, 2019

Online Published: June 26, 2019

URL: https://doi.org/10.5430/ijba.v10n4p64

\begin{abstract}
This theoretical paper aims to introduce and discuss the role of the social marketing as a tool to decrease the index of violence between supporters and improve the satisfaction, well-being and quality of life of fans (as a whole) in the stadium. Understanding the violence in the stadium as a social problem; social marketing becomes a relevant instrument to decrease the violence between supporters since behaviour change is the core concept. Social marketing principles use ideas to transform a social scenario. Social marketing seeks, in the sports area, to encourage supporters to perform an active role in the well-being process in the stadium, taking into consideration themselves, sports club, public services preservation and non-supporters. The social marketing campaign should be designed by a public organisation using the partnership with the sports clubs or sponsorships to improve the offer of well-being for individuals; however, not providing profits for anyone.
\end{abstract}

Keywords: social marketing, behaviour change, violence in sports, sports fan, ideas

\section{Introduction}

It observes that violence on the football is nothing new. The United Kingdom, for instance, recorded several incidents of violence caused by sports fans between the 1980s and 1990s. In effect, two episodes of violence were the triggers to implement the well-being concept in the stadium. First is the "Heysel tragedy" when 39 supporters died in Belgium following confusions generated by Liverpool supporters before the match between Liverpool vs Juventus by the final of the European Champion Clubs' Cup in 1985, the predecessor of the Champions League. Because of this, English sports clubs were banned from UEFA competitions for five years. Second is the Hillsborough in Sheffield, England, 96 supporters died in a match between Sheffield vs Nottingham Forest by the final of the British Cup in 1989. Then, motivated the British government to act harshly against the violence of supporters pre, during and after matches in British stadiums (Carnibella, et al 1996). The government ruled the banning of fans involved in episodes of violence related to sports, e.g., the punished hooligans needed to report to a police station at the time their sports teams are playing. When the departure is abroad, it is necessary to hand over the passport to the police five days before the match. Besides, security cameras were installed in the stadium to assist in identifying violent supporters. Finally, another decision was taken to deal with the hooligans, for example, the presence of police officers infiltrated among the fans (Cleland \& Cashmore, 2016; Spaaij, 2007).

The report of the incidents of violence is over the world. For instance, between January and July, 11 fans died pre, during and after matches regarding the Brazilian League in 2017, besides, 500 supporters were arrested. In 2016, 16 followers died (Costa, 2017). The Brazilian law system is not so strict as the British ones. Every stakeholder lose with incidents of violence pre, during and after matches in the stadium, for instance: a sports club achieves fewer revenues and profits; a sports fan cannot enjoy the time supporting his/her sports team; the sponsors and partners tend to do not invest money and resources in leagues which do not promote their brands; the government need to spend money to fix de public transportation which is damaged by violent supporters, as well as, in public health to care those fans who need some assistance; an ordinary citizen who needs a public transportation in a better condition the next day to go the work, school, university, etc. In sum up, the incidents of violence are a sort of public social cause, i.e., a public problem which demands a solution which lies in the fans' behaviour. Strict rules and punishments are two options which were implemented by the British government, but they do not work using the individual's behaviour as the primary condition. However, understanding that violence (of supporters) are part of a social 
problem of a given society, these authors would like to introduce a third option, social marketing principles.

Social marketing is understood as the marketing strategies applied to ideas, causes and social programs (Kotler \& Lee, 2008). Social marketing principles should be used when voluntary behaviour change is the goal, and social marketers desire an audience-focused program. Social marketing cannot be used if the proposal is only trying to educate or raise awareness of sports fans. Although, if the hope is that education or awareness will lead to behaviour change of supporters, social marketing can be appropriate (Andreasen, 2006). Social marketing has models and concepts and ideas ready-made that the professional can apply to social causes (or problems). Social marketing is recommended in the public sector to develop a social campaign lined up to a social cause. But, there is a wide range of social marketing models to draw on: the choice of models depends on the program's goals, the country, the context, the level of investment, and time frame (Silva \& Mazzon, 2016b). Then, taking into consideration that the violence of supporters is a result of a social cause or problem, how social marketing may assist in decreasing the violence index caused by supporters and in promoting the satisfaction, well-being and quality of life of fans (as a whole) in the stadiums? Thus, this paper aims to introduce and discuss the role of the social marketing as a tool to decrease the index of violence of the supporters and improve the satisfaction, well-being and quality of life of fans (as a whole) in the stadium.

\section{Social Marketing Orientation}

Social marketing is a marketing application to induce, encourage and promote social change entirely, rather than provide ideas or information, e.g., cognitive change; otherwise, education and promotion would be enough to solve the issue (Lefebvre, 2011). Social marketing depends on the other theories for achieving its goals, whence, the social change and behaviour change theories are borrowed to understand the individual and society. These theories added to social marketing enable their professionals to measure, analyse and assess the issues that lead individuals to take decision for social well-being, whose aim is to improve living conditions; reduce possible social inequalities; balance costs of public resources; and move staff to solve the public and social problem, e.g., violence on the football (Henley, Raffin \& Caemmerer, 2011).

Social marketing uses commercial marketing strategies, to influence voluntary (no force or coerce) behaviour change (it is not just increasing awareness or knowledge) and promotes an end goal of improving personal well-being as well as the society as a whole. Thereby, social marketing orientation establishes as practices for public managers (in partnership with the private sector, as a sports club) to lead and keep a healthier and sustainable relationship with their target audience (Kotler \& Lee, 2008). The customer-orientation can provide a set of tools useful to social causes to assist professionals in managing the best way possible the public social (and private, on some occasions) resources to reach the most significant results; undertake a new platform of the concept of exchange in the social area; and provide an innovative tool to get performance in the relationship with fans-consumers (Gordon \& Moodie, 2009).

Since the $1^{\text {st }}$ world conference about social marketing in Brighton in 2008, several studies have been developed around social marketing practices. Previously, the discussion was: What is social marketing? Recently, the debate has taken another perspective: social marketing is not education and/or promotion (Gordon, 2011). Scholars believe that the progress of social media has widened the misunderstanding about the concept because social marketing has been defined as an alternative to inform individuals about social problems and issues. For Dan (2010), such definitions disaffirm the social change standpoint as one of the axes that hold social marketing principles. The social marketers help individuals to make positive change through social change characteristics. Social marketing is a utility package related to activities, processes and effort to deliver benefits to individuals. Thus, social marketing is not just communication or media.

Indeed, social marketing is transforming the social reality of a given society through actions, attitudes, ideas and behaviours that reflect on the individual the opportunity of a healthy living pattern, with purposes to ensure through marketing strategies, the desired and planned behaviour change (Silva \& Mazzon, 2016a). Thus, social marketing is to recognise a social cause and make use of tools to solve it, yet, respecting the free will, desires and decisions, even if they are contrary to the proposed benefits of behaviour change. Social marketing defends the principle that behaviour change should arise out of individuals because they are the active element of the process and not be imposed on them at any cost (Wood, 2012). If behaviour change does not happen, for instance: social marketers, consider if the individuals did not understand the benefits of change; the benefits of change were not well designed; the individuals perceive the benefits but are not willing to leave their lifestyle to practice the change (Bernhardt, Mays \& Hall, 2012). For Andreasen (1994), any organisation (public or private) has permission to prepare social marketing campaigns to promote the behaviour change without aiming at getting profit. Concerning the violence in sports, a partnership between public and private sectors (sports clubs and sponsorships) may be appropriate to design a solution by social marketing campaigns. 


\section{Social Marketing Campaign}

The social marketing campaign has a behavioural goal. Social marketers want to change behaviour (e.g. individuals are doing one thing; social marketers want them to do another). Social marketing aims to benefit an individual or society overall. If individuals are safer and healthier, they will put less of a strain on the public government. If supporters are friendly in the matches, each one supporting their sports team, security systems, strict rules became less necessary, as well as public services, are preserved (Firestone et al, 2017). But, if these things are ever going to happen, society needs some help. Fans must change their behaviour; then, behaviour change is what social marketing proposes for them. Indeed, there are thousands of ways to work towards social goals, but not all involve social marketing practices. Attempts to accomplish social objectives can be divided into two categories: behavioural and non-behavioural. Preventing incidents of violence, they could install camera and security structures, also use more officers to oversee the fans (non-behavioural), or one could persuade more supporters to be friendly and enjoy the time in the match day (behavioural). Non-behavioural solutions tend to be in technology; and behavioural solutions often require social marketing (Andreasen, 2006; Kotler \& Lee, 2008; Smith \& Strand (2009).

How does social marketing work? Smith \& Strand (2009) introduce through Figure 1, where each process above the dotted line is involved in changing behaviour. The behaviour is the goal, i.e., the specific action the social marketers want a particular audience to undertake. Whether fans engage in such behaviour is based on how they view that decision, or their perceptions: What are the benefits? Does it seem challenging to do? Can someone like me do it? Are other supporters doing it? Will individual laugh at me if I do it? Trying to figure out which perceptions influence a behaviour (known as determinants) is the challenge of social marketing. If social marketers are unaware of which determinants affect behaviour, they cannot understand what sort of marketing solution will be required. It is essential to identify what supporters view as benefits and as barriers correctly. The benefit is something that individuals want. Some benefits might include an improved self-image, good health, peace of mind, convenience and the approval of fans who matter. The barrier is something that stands between an individual and an action. These barriers may be monetary or non-monetary costs.

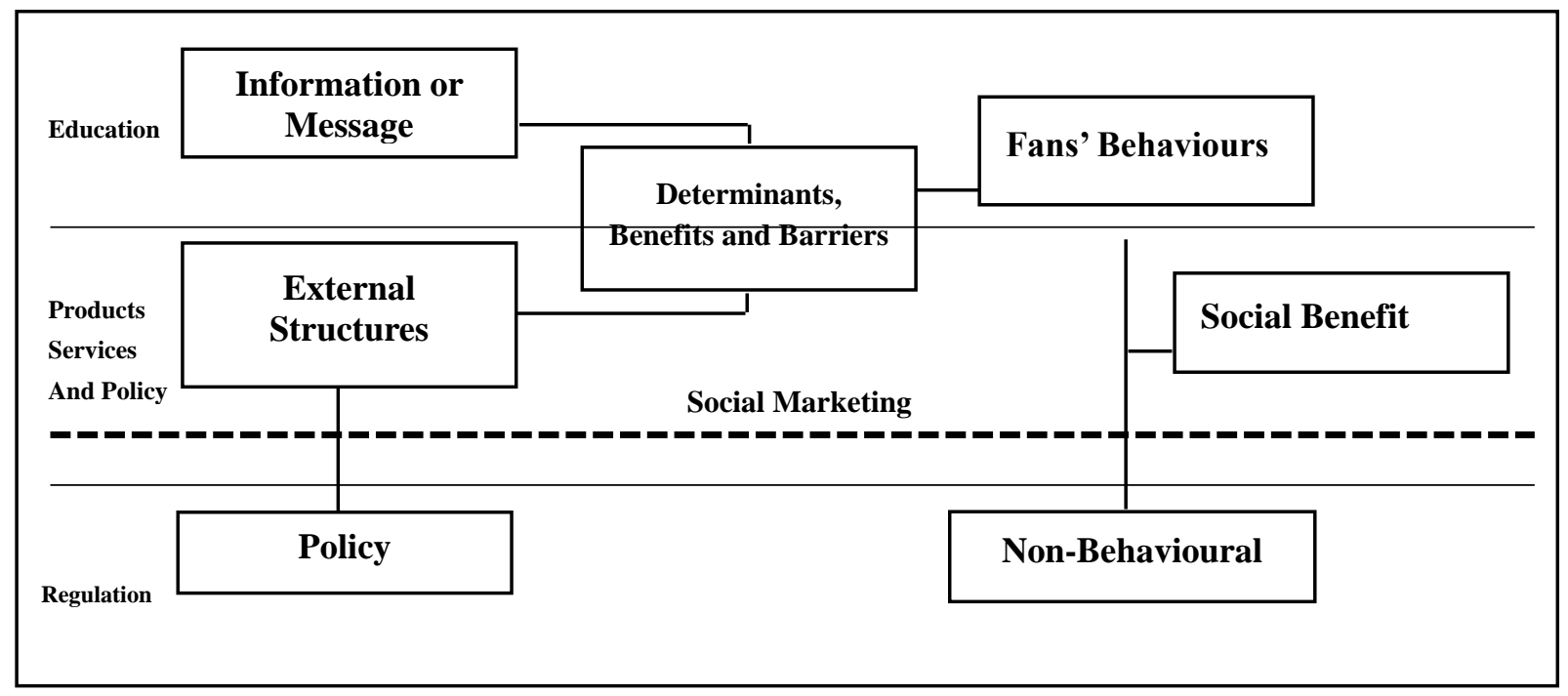

Figure 1. Social marketing framework

Source: Smith and Strand (2009)

Rothschild, Mastin \& Miller (2006) believe that there are three classes of behaviour change problems: education, regulation and marketing. Indeed, the most common reason for the failure of social marketing programmes is the focus on education problem, leaving out rules required for a marketing solution and ignoring the power of the marketing mix to help supporters make behaviour change. The characteristics of these three problems are listed below. To help identify which category of the problem the programme will address, the Social Marketer should use all the data collected about the issue and the potential audiences.

- Education problems: supporters need some basic facts to change. Behaviour is relatively simple. Action 
requires no outside resources. It is not in conflict with the dominant societal norm, nor does it carry any significant stigma. It has benefits that are apparent to the audience, but the audience lacks basic understanding (e.g. respect the other fans);

- Regulation problems: behaviour is challenging to perform. Understanding of behaviour is widespread, and multiple attempts have been made to influence it voluntarily. Specific patterns of behaviour can cause significant damage to society, and there is now a consensus it should be regulated. Thus, do not limit your thinking of regulations to the government forbidding certain actions; regulation can take many forms. Indeed, it can control by discouraging individual behaviour like destroy public transportation (e.g. punishment for those who destroy stadium facilities and public services);

- Marketing problems: behaviour is somewhat complex; fans need knowledge, values, principles and/or new skills to perform it well. It is not widely accepted, although it is often widely known. It has significant immediate barriers and few immediate benefits people care about (e.g. a level of scholarship - or education - recognise what is right and wrong).

The stages of change theory, also called the transtheoretical model, assists in explaining how the fan's behaviour change. Thus, this theory was developed after studying how a supporter becomes friendly and has been used since to understand other complex behaviours, such as the origin of the violence between supporters. The stage of change theory states that fans go through a process, on their own and in their way, of changing to new behaviour. At each stage, they may have unique needs. For example, someone in the pre-contemplative stage may need information about behaviour but is not ready to discuss how to integrate the behaviour into his or her daily life (Prochaska \& DiClemente, 1983; Prochaska, 2008). The five stages are as follows:

- Pre-contemplative: individuals in this stage do not intend to change their current behaviour in the foreseeable future, are unaware of the benefits of changing their behaviour, or deny the consequences of their current behaviour;

- Contemplative: individuals are aware that a change might be useful, are seriously thinking about changing their behaviour, but have not yet committed;

- Preparation/decision-making: individuals intend to take action shortly and may have made some inconsistent action in the recent past;

- Action: individuals modify their behaviour, experiences, or environment to overcome the problem; the behaviour change is relatively recent;

- Maintenance: individuals work to prevent relapse and maintain behaviour change over an extended period.

The purpose of social marketing is to produce behaviour change. Nevertheless, when adding social behaviour to fan's perspectives, the emphasis on creating attractive exchanges encourages changes through a value proposition (when the friendly outweigh the violence). Social behaviour is a guide for all action plans to be developed by social marketers. These behaviour changes are assessed by the degree of difficulty of the social marketing campaigns to obtain favourable results. Thus, social marketing is intended to solve social issues, which require attention, acceptance and individual's effort as well as the societies (Kotler \& Lee, 2008). Then, the focus on social marketing in sports events is convincing a supporter to adopt behaviour changes.

In social marketing in the sports context, the fan is an active participant in the exchange process; and the exchange happens when the two sides (supply and demand) seek to satisfy their needs in their way. Peattie \& Peattie (2009) believe that social marketing has some essential elements that define its performance in terms of efficiency and effectiveness: an author: someone who produces and sponsors the campaign, i.e., government, sports club, sponsorships and partnerships, etc; a reason: the act of making campaign available to someone; an offer: product, service and behaviour; an act: in which context it happens; a target audience: the intended and unintended consequences. Due the implications and processes of planning a social marketing campaign, it is recommendable for social marketers to include social and society variables to understand social causes: dwelling, literacy, social capital, working condition, public, policy and resources to prepare the behaviour changes and then social products.

\section{Social Change: The Objective of Social Marketing}

The social change happens when a transformation modifies the previous state of any social reality. Thus, what are the assumptions of social change? First, being a collective phenomenon, in which may be identifiable in time; second, having a permanent nature and complexity involved and only established when conducting a preliminary disorganization of the previous situation; third, changing itself does not always entail an improvement, in other hand, an improvement still produces a sort of change; fourth, combining the idea of change with the idea of progress to 
reflect the desirable direction of social change, then, lead the improvement in living conditions. The social change comes up of the internal determinants when these arise of consequences of conflicts or needs of society itself, and external as result of a relationship with other societies (Kotler, 1975; Lefebvre \& Flora, 1988; Marchioli, 2006).

Then, if the goal is not social change, it is not social marketing. If added the fans customer perspective, arise the emphasis on the concept of exchange with the purpose to encourage behaviour change through benefits using acceptable costs (Andreasen, 2006). The product is unlike any other marketing since the social marketing aims to promote social well-being, quality of life, social justice, reducing social inequalities and assisting individuals to have a happiest and healthiest life (Wymer, 2011). Thus, social change is an organised effort by an organisation to influence individuals to accept, alter and reject specific ideas, attitudes, customs and behaviours. Therefore, social change or behaviours theories are used in social marketing strategies to understand the individuals (campaign targets) (Kotler \& Lee, 2008).

For elucidating, two theories will be introduced, as to suggest Table 1. The social change theory is organised as follow: cognitive, action, behaviour and value, in this order by Kotler (1975); and behaviour change, in the order by Prochaska \& DiClemente (1983). The six stages are as follows: pre-contemplative: individuals in this stage do not intend to change their current behaviour in the foreseeable future, are unaware of the benefits of changing their behaviour, or deny the consequences of their current behaviour; contemplative: individuals are aware that a change might be useful, are seriously thinking about changing their behaviour, but have not yet made a commitment; preparation/decision-making: individuals intend to take action in the near future and may have taken some inconsistent action in the recent past; action: individuals modify their behaviour, experiences, or environment to overcome the problem; the behaviour change is relatively recent; maintenance: individuals work to prevent relapse and maintain behaviour change over a long period; termination: individuals took behaviour up on a lifestyle.

Table 1. Similarities between models of social change and behaviour change

\begin{tabular}{ll}
\hline Kotler (1975) & Prochaska \& DiClemente (1983) \\
\cline { 2 - 2 } Cognitive & Pre-contemplation \\
\cline { 2 - 2 } & Contemplation \\
\cline { 2 - 2 } & Preparation \\
\hline Behaviour & Action \\
\hline Value & Maintenance \\
\hline
\end{tabular}

Sources: Adapted by Kotler (1975) and Prochaska \& DiClemente (1983)

How to prepare a social change in a social campaign to overcome the violence in sports? The social marketers begin the value proposition of campaign and raising awareness in a target audience through ideas and benefits. In summary, it involves the broadcasting of information around the expected change, then, reach the individuals' cognitive making they reflect on the possibilities of changing behaviour. For example, explaining to fans about the importance of respecting the supporters of opponent's team and do not damage the public services (cognitive change), and create an atmosphere pre, during and after matches to encourage and support the sports as fun, and the stadium is the place where fans share their emotion and passion for their sports teams (an action change). But, if the aims involve changing behaviours, the social marketers should encourage and incite the amusement, the game, competition and the friendship between the two groups of supporters and "waive" behaviour that contradicts the leisure proposal of a match (behaviour change). However, the changing beliefs and values concerning well-being in the sports area lie the most significant challenge. It is hardly encouraging the relationship and friendship between opponent sports fans due to the sense of competition, emotional and passion, i.e., supporting the team is essential for supporters (value change) (Kotler, 1975; Kotler \& Lee, 2008). The development is similar to the Prochaska \& DiClemente (1983) model.

However, before to implement a social change, it is relevant to know two sorts of behaviour determinants about the fans (target audience) in a given social campaign (Smith \& Strand, 2009): external and internal. First, the external determinants are the forces outside the individual that affect his or her performance of a behaviour, such as skills, the set of abilities necessary to perform a particular behaviour; access, encompasses the existence of products and services, such as helmets and safety seats, their availability to an audience and an audience's comfort in accessing 
desired types of products or using a services; policy, laws and regulations that affect behaviours and access to social products and services; culture, the set of history, customs, lifestyles, values and practices within a self-defined group. May be associated with ethnicity or with lifestyle; actual consequences, what happens after performing a behaviour.

Second, the internal determinants are the forces inside an individual's head that affect how he or she thinks or feels about a behaviour, such as knowledge, basic factual about traffic safety, how protects oneself from injury, where to get services, etc; attitudes, a wide-ranging category for what some individual thinks or feels about a variety of issues. This over-arching category would include self-efficacy, perceived risk, and other attitudinal factors; self-efficacy, an individual's belief about a particular behaviour; perceived social norms, the individual's perception and what he or she thinks regarding adhering to the new behaviour; perceived consequences, what an individual thinks will happen, either positive or negative, as a result of performing a behaviour; intentions, what are individual's plans and projects in respect the future; commitment to a future act. Future intention to perform the behaviour is highly associated with playing that internal behaviour (Lefebvre, 2011; Silva \& Mazzon, 2016b).

According to Gordon (2011) and Marchioli (2006), there are critical considerations for social marketing programs in social area: match the social marketing model to program objectives and country context; ensure coordination among crucial players for effective market segmentation; conduct research to ensure appropriate social marketing program design and implementation; use the power of social marketing to introduce and scale up access to product "benefits"; invest in behaviour change communication; and plan for sustainability at the beginning. Therefore, social marketing is the utilisation of marketing theories and techniques to influence behaviour to achieve a social goal. In other words, social marketing is similar to commercial marketing, except that its purpose is not to maximise profits or sales; the goal is a change in behaviour that will benefit society. The social (or behaviour) change is the ultimate goal in social marketing.

For Cismaru, Lavack \& Hill (2009), social marketing campaigns have been developed and implemented across a broad variety of areas, although the majority and most visible have been and continue to be a lifestyle and social care. Thus, social marketing is appropriate to violence in sports, due to: consumer-oriented from the beginning of the planning process, once the consumer comes first, i.e., the campaigns will be approached from the consumer's perspective; improve the management, implementation and evaluation of intervention programs using an efficient and effective marketing activities through development of plan lined up to the target audience; prepare and broadcast the message of campaign through medias appropriate to get the audience attention; improve public satisfaction using marketing research in order to know the results must be achieved in a given social campaign; and help fans-consumers, once the market analysis enables to figure out what violent behaviour of supporters requires behaviour change.

The social marketing activities have been useful when integrated with intervention programmes in public administration, such as (Henley, Raffin, Caemmerer, 2011; Kotler \& Lee, 2008; Lefebvre, 2011; Rothschild, Mastin \& Miller, 2006; Silva \& Mazzon, 2016a): consumer-oriented planning, since the initial process of intervention in social problems, when managing programmes which raise acceptance in the long term; improving of the management and evaluation of programmes implementation, which should apply an integrated active plan in social marketing; more effective development of information campaign, aiming to achieve the cognitive and get the supporter's attention to the benefits of behaviour change in the campaigns; improving the quality and public satisfaction, in order to identify levels of satisfaction among individuals, detecting problems and trying to understand how programmes can be developed to respond to any complaints and dissatisfaction of individuals; solutions to violence into sports, once the social marketing seeks to solve problems that require attention, acceptance and satisfaction of supporters and non-supporters, to consider the well-being in the stadium and decrease the violence indicators in the football and sports, as a whole.

\section{Final Consideration}

Social marketing is an instrument for encouraging the behaviour change, once social marketing orientation seeks to solve violence issues in sports that require attention and acceptance of an idea, as well as the target audience satisfaction employing social services, balancing the supporters and society needs in which the social programme will be developed. Behaviour change is the motto and the goal of social marketing (Gordon, 2011). On the one hand, it is commendable when a public organisation and sports entity introduce a social marketing campaign while a supporter and non-supporters' well-being proposal (Gordon \& Moodie, 2009). On the other hand, the sports club and sponsorships need to fit the behaviour change as the primary purpose, and not encourage fans' consumption of its products and/or services through benefits like free tickets, support to charitable organisations or investment in social campaigns, as part of public relation program (Andreasen, 2006). These sports club and sponsorship may allege in 
the media that its practices are in social marketing, but, actually, this company is practising another sort of marketing strategy. Sports club and sponsorship as a whole can see philanthropy as a way to gain a positive perception in sports sectors to leverage better outcomes (Bernhardt, Mays \& Hall, 2012).

The objective of social marketing is to become an element of the transformation of fans' behaviour in the sports area, in order to mitigate the violence in the stadium and public services, like public transportation. The social marketing principles can be thought as a systematic and strategic planning process; a social or behaviour change strategy, to address mindset problems and a total package of strategies carefully chosen based on the characteristic of the target audience (Wood, 2012). Social marketing borrows commercial marketing and social change theories to set a marketing application for intervention in the social issue. Social marketing is not just advertising or communication, a media campaign, reaching everyone and a fast process, since the entire processes depend on the supporter's active role (Silva \& Mazzon, 2016b). In summary, a social marketing plan requires to manage some assumptions before preparing an execution plan, for instance: to define a consumer-oriented culture through a mission and a goal; to understand consumer behaviour through research, information system and external and internal environment to track current issues which characterise the supporters; to set the behaviour goal as well as the change processes; to map the competition - barriers; to know how to establish the concept of exchange; to define the target audience and the positioning of the benefit; to set up the social marketing mix; to create performance index to monitor, analyse and assess the social campaign in the sports area (Silva \& Mazzon, 2016b).

Then, social marketing arises as an alternative to introducing customer orientation backed by integrated marketing to promote fan-consumer satisfaction through behaviour change in the stadium in the sports area. On the one hand, social promotion and prevention are cheaper for the State; on the other hand, it is more complicated. Social marketing aims to preserve public resources since it works in well-being. Notice that in the sports area, a social marketing campaign requires a partnership and relationship with sports clubs, supporters and society as a whole, with the purpose of the promoting benefits for both and improving the quality of life. Behaviour change is a guide for all action plans to be developed by social marketers. These behaviour changes are assessed by the degree of difficulty of the social marketing campaigns in order to reach favourable results. Social marketing is intended to solve social issues, which require attention, acceptance and supporter's effort as well as society. Thus, social marketing is a tool to promote the intervention in the sports area and peace in the stadium through ideas (voluntary behaviour) instead of rules and punishments (involuntary behaviour). The sports progress while an entertainment or leisure comes from the awareness of supporters and not from legal intervention. Public management is responsible for designing the social marketing plan; however, it is not possible if sports entities and sponsorships participate.

\section{References}

Andreasen, A. (2006). Social Marketing in the 21st Century. Thousand Oaks: Sage Publications, Inc.

Andreasen, A. R. (1994). Social Marketing: Its Definition and Domain. Journal of Public Policy \& Marketing, 13(1), 108-114. https://doi.org/10.1177/074391569401300109

Bernhardt, J. M., Mays, D., \& Hall, A. K. (2012). Social Marketing at the Right Place and Right Time with New Media. Journal of Social Marketing, 2(2), 130-137. https://doi.org/10.1108/20426761211243964

Carnibella, G., Fox, A., Fox, K., McCann, J., Marsh, J., \& Marsh, P. (2017, October 10). Football Violence in Europe: A Report to the Amsterdam Group. Social Issues Research Centre. Retrieved from http://www.sirc.org/publik/football_violence.pdf

Cismaru, M., Lavack, A. M., \& Hill, P. J. (2009). Social Marketing Campaigns Aimed at Preventing Drunk Driving. International Marketing Review, 26(3), 292-311. https://doi.org/10.1108/02651330910960799

Cleland, J., \& Cashmore, E. (2016). Football Fans' View of Violence in British Football: Evidence of a Sanitized and Gentrified Culture. Journal of Sport and Social Issues, 40(2), 124-142. https://doi.org/10.1177/0193723515615177

Costa, G. (2017). Why so many People Dying? UOL Sports Channel. Retrieved from https://www.uol/esporte/especiais/especial-violencia-torcedores.htm\#por-que-tantas-mortes

Dann, S. (2010). Redefining Social Marketing with Contemporary Commercial Marketing Definitions. Journal of Business Research, 3(2), 147-153. https://doi.org/10.1016/j.jbusres.2009.02.013

Firestone, R., Rowe, C. J., Modi, S. N., \& Sievers, D. (2017). The Effectiveness of Social Marketing in Global Health: A Systematic Review. Health Policy Planning, 32, 110-124. https://doi.org/10.1093/heapol/czw088

Gordon, R., \& Moodie, C. (2009). Dead cert or Long Shot: The Utility of Social Marketing in Tackling Problem 
Gambling in the UK?. International Journal of Non-profit and Voluntary Sector Marketing, 14(3), 243-253. https://doi.org/10.1002/nvsm.350

Gordon, R. (2011). Critical Social Marketing: Definition, Application and Domain. Journal of Social Marketing, 1(2), 82-99. https://doi.org/10.1108/20426761111141850

Henley, N., Raffin, S., \& Caemmerer, B. (2011). The Application of Marketing Principles to a Social Marketing Campaign. Marketing Intelligence \& Planning, 29(7), 697-706. https://doi.org/10.1108/02634501111178712

Kotler, P., \& Lee, N. (2008). Social Marketing: Influencing Behavior for Good ( $3^{\text {rd }}$ ed.). Thousand Oaks: Sage.

Kotler, P. (1975). Marketing for Nonprofit Organizations. Englewoods Cliffs, New Jersey: Prentice-Hall.

Lefebvre, R. C., \& Flora, J. A. (1988). Social Marketing and Public Health Intervention. Health Education Quaterly, 15(3), 299-315. https://doi.org/10.1177/109019818801500305

Lefebvre, R. G. (2011). An integrative Model for Social Marketing. Journal of Social Marketing, 1(1), 54-72. https://doi.org/10.1108/20426761111104437

Marchioli, A. (2006). Marketing Social et Efficacité des Campagnes de Prévention de Santé Publique: Apports et Implications des Recénts Modèles de la Communication Persuasive. Communication \& Marketing, 1, 17-36. https://doi.org/10.3917/mama.031.0017

Peattie, K., \& Peattie, S. (2009). Social Marketing: A Pathway to Consumption Reduction? Journal of Business Research, 62, 260-268. https://doi.org/10.1016/j.jbusres.2008.01.033

Prochaska, J. O., \& DiClemente, C. C. (1983). Stages and Processes of Self-change of Smoking. Toward and Integrative Model of Change. Journal of Consulting and Clinical Psychology, 51, 390-395. https://doi.org/10.1037/0022-006X.51.3.390

Prochaska, J. O. (2008). Multiple Health Behavior Research Represents the Future of Preventive Medicine. Preventive Medicine, 46, 281-285. https://doi.org/10.1016/j.ypmed.2008.01.015

Rothschild, M. L., Mastin, B., \& Miller, T. W. (2006). Reducing Alcohol-Impaired Driving Crashes Through the Use of Social Marketing. Accident Analysis \& Prevention, 38(6), 1218-1230. https://doi.org/10.1016/j.aap.2006.05.010

Silva, E. C., \& Mazzon, J. A. (2016). Developing Social Marketing Plan for Health Promotion. International Journal of Public Administration, 39(8), 577-586. https://doi.org/10.1080/01900692.2015.1023447

Silva, E. C., \& Mazzon, J. A. (2016). Is Social Marketing Experiencing an Identity Crisis? International Journal of Marketing Studies, 8(3), 22-32. https://doi.org/10.5539/ijms.v8n3p22

Smith, W. A., \& Strand, J. (2009). Social Marketing Behavior: A Practical Resource for Social Change Professionals. Washington, DC: Academy for Educational Development (AED).

Spaaij, R. (2007). Football, Hooliganism as a Transnational Phenomenon: Past and Present Analysis: A Critique More Specificity and Less Generality. The International Journal of the History of Sport, 24(4), 411-431. https://doi.org/10.1080/09523360601157156

Wood, M. (2012). Marketing Social Marketing. Journal of Social Marketing, 2(2), 94-102. https://doi.org/10.1108/20426761211243937

Wymer, W. (2011). Developing more Effective Social Marketing Strategies. Journal of Social Marketing, 1(1), 17-31. https://doi.org/10.1108/20426761111104400 